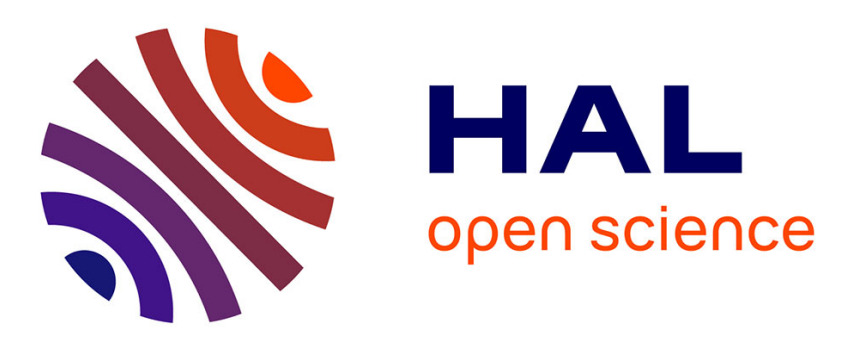

\title{
Instruments and Sounds as Objects of Improvisation in Collective Computer Music Practice
}

\author{
Jerome Villeneuve, James Leonard, Olivier Tache
}

\section{To cite this version:}

Jerome Villeneuve, James Leonard, Olivier Tache. Instruments and Sounds as Objects of Improvisation in Collective Computer Music Practice. CMMR 2019 - 14th International Symposium on Computer Music Multidisciplinary Research, Oct 2019, Marseille, France. hal-02270852

\section{HAL Id: hal-02270852 \\ https://hal.science/hal-02270852}

Submitted on 3 Feb 2020

HAL is a multi-disciplinary open access archive for the deposit and dissemination of scientific research documents, whether they are published or not. The documents may come from teaching and research institutions in France or abroad, or from public or private research centers.
L'archive ouverte pluridisciplinaire HAL, est destinée au dépôt et à la diffusion de documents scientifiques de niveau recherche, publiés ou non, émanant des établissements d'enseignement et de recherche français ou étrangers, des laboratoires publics ou privés. 


\title{
Instruments and Sounds as Objects of Improvisation in Collective Computer Music Practice
}

\author{
Jerome Villeneuve ${ }^{1}$, James Leonard ${ }^{1}$, Olivier Tache ${ }^{2}$ \\ 1 Univ. Grenoble Alpes, CNRS, Grenoble INP, GIPSA-Lab, 38000 Grenoble, France \\ 2 Independent researcher, Grenoble, France \\ jerome.villeneuve@gipsa-lab.fr
}

\begin{abstract}
This paper presents the authors' first attempt at a new (and unexpected) exercise: that of observing, contextualising and problematising their own collective Computer Music experiences. After two years practising emergent collective improvisation in private and public settings, which has led the authors to fundamentally reconsider both individual and collective musical creation, came the desire to methodologically deconstruct this process - one that they never anticipated and, until now, had never formalised. By starting from the very notions or performance and improvisation in the context of Computer Music, and crossing prolific literature on these topics with humble observations from their own experience, the authors then elaborate on what appears to them as the most enticing perspective of this creative context: the systematic improvisation of both their tools and sounds in an unique flow.
\end{abstract}

Keywords: Computer music, free improvisation, collective experimentation, instrument and sound improvisation, live patching

\section{Introduction}

This paper aims to question collective sound-improvisation in the context of digital technologies, based on a practice shared by the authors over the last two years. More specifically, from the perspective of three current or ex computermusic researchers all previously involved in various more traditional musical activities (from heavy metal to jazz), we will try to analyse how spontaneous musical interaction led us towards a free-form computer-based collective improvisation project named Orcæ - and the many interrogations that have emerged throughout collective practice and performance. As such, the paper is both a subjective testimony and a first attempt to methodologically deconstruct this shared practice in light of existing literature as well as the authors' musical and technological backgrounds. Starting from a brief overview and description of Orcæ's genesis and current creative process, we will work our way towards more fundamental questions such as: how do we behave collectively when improvising experimental electronic music? What can collective Computer Music performance mean? And can the notion of free-improvisation be extended to improvising the computer-based instrument itself? 


\section{A brief presentation of our study material: Orcæ}

Orcæ is a trio of musicians composed of the authors that practices free collective music improvisation using mainly computers. Each of us has a different history of musical practices, including such diverse styles as heavy metal, jazz, reggae, chanson française, rock or electro-dub. Although we had never played music together before forming the band, we have a common experience as researchers in Computer Music and Digital Arts, having prepared PhDs and worked in the same team during a 5-to-10-year period. After several discussions regarding playing music together over the years, the project was initiated in January 2017.

\subsection{Beginnings and gravitation towards free improvisation}

The initial purpose of Orcæ was to combine the authors' instrumental practices - namely guitar, keyboards and drums - with the idea of playing and performing post-rock music. Some songs were written beforehand, whereas other ideas were to emerge through recorded improvisation sessions, then to be transcribed and progressively fixed into song format. However, after recording and noting down a few improvised structures, attempts to reproduce them at a later time proved rather fruitless and frustrating: we all felt that something was "lost in translation", that re-exploring the same sounds was never as fun and exciting... Gradually, the electronic drumset became evermore drowned in post-processing and effects, before being abandoned in favour of a simple laptop. Similarly, fixed keyboard virtual instruments were replaced by a modular sound-synthesis environment, and the guitar became accompanied (and often replaced) by a laptop running sound transformation patches. Not only the music couldn't be written, but the instrument line-up itself was constantly evolving, sometimes expanding, other times shrinking. The progressive mutation was never planned, never completely grasped and never formally discussed by the players. After approximately 6 months of weekly sessions, our practice started to stabilise into the collective's present workflow.

The players each have different musical backgrounds, relationships towards improvised music (see Figure 1). It is worth noting that although we all come from a sound-synthesis technical background, most of our musical activity has been in current popular music genres (exception made of one or two electroacoustic fixed-piece compositions), and that only of us had any significant prior experience - or real interest - in free form (or self-idiomatic) improvised musical practice before this project. The music production tools used by each member within Orcæ also differ: Player A relies on $\operatorname{Max} / M S P^{3}$, Player B creates mostly using Reason ${ }^{4}$, and finally Player C uses Ableton Live ${ }^{5}$.

\footnotetext{
${ }^{3}$ A modular patching environment for music and digital creation: cycling74.com/products/max

4 The digital audio workstation (DAW) by Propellerhead: www.propellerheads.com/en/reason

${ }^{5}$ Arguably the most popular DAW for producing electronic music: www.ableton.com/en/live/
} 


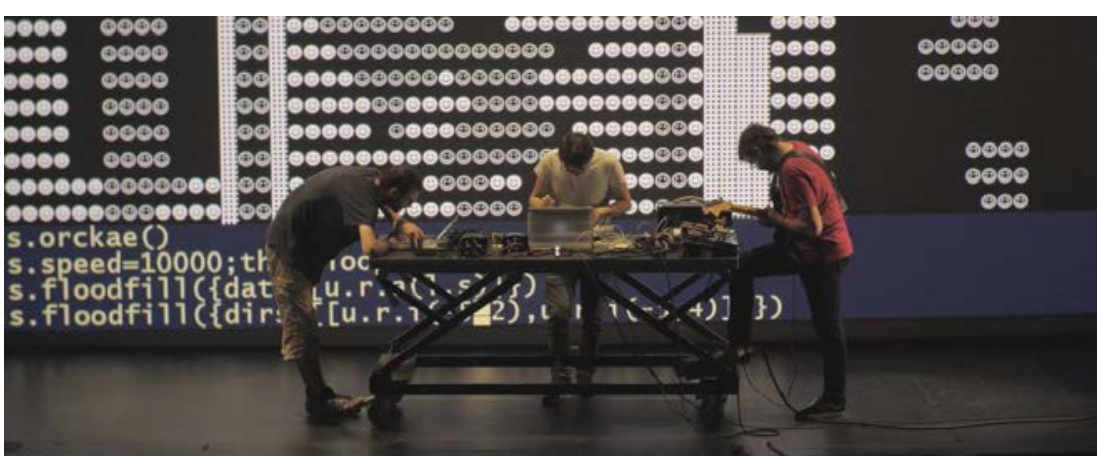

\begin{tabular}{|l|l|}
\hline Player A & \multicolumn{2}{|l|}{$\begin{array}{l}\text { Musical } \\
\text { experience \& } \\
\text { training }\end{array}$} & $\begin{array}{l}\text { Self-taught guitarist, formerly focused on heavy rock and metal: } \\
\text { written music, rehearsed regularly and rendered "as is" live. Short } \\
\text { spell in the Grenoble Conservatory's composition class. }\end{array}$ \\
\hline Background & $\begin{array}{l}\text { Software engineer \& Computer Music PhD. Also sound engineer } \\
\text { (mostly producing bands from punk to metal). }\end{array}$ \\
\hline $\begin{array}{l}\text { Link to } \\
\text { improvisation }\end{array}$ & $\begin{array}{l}\text { Small amount of jazz improvisation during first years of guitar play- } \\
\text { ing - a skill now completely lost. }\end{array}$ \\
\hline $\begin{array}{l}\text { Instruments } \\
\text { used in Orca }\end{array}$ & $\begin{array}{l}\text { Electric guitar and various effect pedals } \\
\text { Max/MSP patches with control surface. }\end{array}$ \\
\hline
\end{tabular}

\begin{tabular}{|c|c|}
\hline Player B & \\
\hline $\begin{array}{l}\text { Musical } \\
\text { experience } \mathcal{E} \\
\text { training }\end{array}$ & $\begin{array}{l}\text { Self Self-taught musician, has successively played guitar, drums and } \\
\text { keyboards in a now-defunct electro-rock band, before turning to solo } \\
\text { electronic music production. }\end{array}$ \\
\hline Background & $\begin{array}{l}\text { Software engineer \& software engineer, } \mathrm{PhD} \text { in Computer Music, } \\
\text { former Pure Data /DAW teacher. }\end{array}$ \\
\hline $\begin{array}{l}\text { Link to } \\
\text { improvisation }\end{array}$ & $\begin{array}{l}\text { Has practiced some free collective improvisation with his previous } \\
\text { band (non-public jam sessions) and one-person improvisation as a } \\
\text { way to compose electronic music. }\end{array}$ \\
\hline $\begin{array}{l}\text { Instruments } \\
\text { used in Orca }\end{array}$ & Reason, and very recently Max/MSP. \\
\hline
\end{tabular}

\begin{tabular}{|l|l|}
\hline Player C & \multicolumn{2}{|l|}{$\begin{array}{l}\text { experience \& } \\
\text { training }\end{array}$} & $\begin{array}{l}\text { Formal education percussion, drums and piano, then jazz school. } \\
\text { Drummer in various projects (ska-punk, big-band, raeggea, chanson } \\
\text { française and Klezmer). Confidential electronic music composition. }\end{array}$ \\
\hline \hline Background & Computer Music PhD with a background in physics. \\
\hline $\begin{array}{l}\text { Link to } \\
\text { improvisation }\end{array}$ & $\begin{array}{l}\text { Systematic tendency to improvise when sitting behind drums, re- } \\
\text { gardless of rehearsal or public contexts. }\end{array}$ \\
\hline $\begin{array}{l}\text { Instruments } \\
\text { used in Orca }\end{array}$ & $\begin{array}{l}\text { Ableton Live, always starting from the default patch at the begining } \\
\text { of an Orcae session. Zero external controler. }\end{array}$ \\
\hline
\end{tabular}

Fig. 1. Above: Photo of a live performance in May 2018. Live-coded visuals were generated by Maxime Bouton and Emile Greis. Below: profile of each member of Orcæ. 


\subsection{Workflows and practices}

Private Sessions start as soon as each member has connected their instrument to the main sound card and has a pair of headphones on. There are usually no directives exchanged between the members : we just start playing. One of us may occasionally propose a specific constraint (e.g. "let's not use any distortion today"), but most of the time such constraints are self-imposed as a way to avoid repetition and foster creativity. The session usually ends by an implicit common agreement, after anything from 40 minutes to well over an hour : sounds fade out, then one of us takes his headphones off, quickly followed by the others.

Public Sessions or performances were envisaged later (after nearly a year of playing together) and are handled a little differently. Before each performance, members usually exchange a few words about the global mood that the music may aim to achieve (although we rarely manage to stick to what we discuss beforehand). We are usually not aware of what other members have prepared (or in mind) for the performance, and enjoy having a few "tricks up our sleeves" for the others. Additionally, it is quite common for us to communicate verbally during public performances (e.g. "let's slow down") - while we hardly never do so in private sessions - particularly when trying to plan a "come down" for the closing minutes of the performance, as there are generally strict time limitations.

Multi-track Recording is systematic and has been since the very beginning of Orcæ, for both public and private sessions. This material is exploited to produce fixed audio tracks that we publish on the internet. The production process is kept as simple as possible so that the results resemble what can be heard live during a session, while filtering out certain inevitable moments were we are in more of a sonic research process than in a musical one. This work mostly consists in listening to raw material, selecting interesting portions and preparing them with limited editing and mixing as a stereo file (generally lasting from 3 to 15 minutes). We rarely desynchronise tracks, in order to keep the energetic cohesion from the collective improvisation. We are also rather attached to listening to the raw unedited recordings of our sessions, and have published a small amount of them, usually from public performances.

Collaborations have occurred regularly since the earliest stages of the project, through additional players occasionally performing with us as guests. We have worked with musicians and vocalists, video makers (in the context of producing spontaneous soundtracks for a short film playing in a loop during the session, or someone improvising live with us using a wide range of pre-recorded video capsules) and even live coders for real-time image generation. The latter have been a steady collaboration (both during private and public sessions). 


\section{Collective Computer Music Performance and Improvisation}

In the following section, we will use Orcæ's creative process as a basis for analysing fundamental questions of performance and improvisation in collectivelypracticed Computer Music. We propose to reflect upon these elements by combining various positions and results from the corresponding literature with interrogations and observations related to our personal practice. Although the acts of performance and improvisation are highly linked in this case, they will first be treated separately, as each bring forward a number of specific questions.

\subsection{Performance}

Performed Computer Music can designate any number of things. Our background lies in experimental music and academia. However we will consider here any public representation in which music is (at least seemingly) produced in the presence of a computer - englobing everything from electroacoustic contemporary music, to popular DJs, underground artists, to Laptop Orchestras and NIMEs ${ }^{6}$.

Authenticity Computer Music performance in many of these contexts can spark a certain degree of confusion or skepticism among audiences since, as Andrew Schloss [1] remarks, it is not always possible for spectators to "understand the performance from a direct/physical standpoint". It is indeed not trivial for an audience to know if all or part of the sounds that they are hearing are being generated through live performance, or if they are simply pre-recorded and then played back. To Schloss, this situation is deceitful: "Tape music was boring to watch, but at least it was honest, with no false expectations of performance". He decries "knob twiddling" and other computer performance gestures that display no visual effort as things that should be either predetermined beforehand or discretely (and anonymously) performed behind the mixing desk.

Role of a Human Performer Schloss' primary focus is to bring back certain theatrics of effort and of corporeal causality from gesture to sound, a goal shared by much of the academic research on NIMEs, and by most of today's popular electronic music performers. One could argue that the question of ergonomics allowing the performer to finely control a Digital Musical Instrument is sometimes superseded by the question of representing and conveying "readable" gestural efforts for the sake of the observer/audience. One way or the other, designing meaningful corporeal links from gesture to sound in modern music is often problematic as a) one-to-one gesture-sound mappings are easily understandable but rarely sufficient for the musical discourse and b) complex gesture-sound mappings (e.g. triggering complex sound processes by means of relatively simple

\footnotetext{
${ }^{6}$ New Instruments for Musical Expression - conference: www.nime.org
} 
gestures) can generate even more frustration from the observer, who is spectator to seemingly abstract gestures, perceptively unlinked to the sonic result.

For Guy Garnett [2], the human performer harbors more fundamental aesthetic consequences, such as the gestural nuance generally associated with human instrumental performance, rarely present in electroacoustic tape music:

it is more difficult to incorporate "performative" inflection into tape music, and therefore, for practical reasons, it becomes less likely to occur. [...] because [these subtleties] are difficult to produce, there is a definite tendency to avoid them.

Garnett also underlines the physical and cognitive constraints of human performance that affect the composer, the performer and the listener:

The performance gestures [...] must be cognizable: the performer must be able to get their mind around them in some way. The composer without physical limitations of performance can more easily convince himself or herself that they have created something real and comprehensible, whereas what they have may be an unhearable ideal. It is relatively easy to create algorithms that generate sounds whose qualities as music are inscrutable, beyond the cognitive or perceptive abilities of listeners.

One can therefore conclude that human performance in Computer Music is not only a question of adding readability to a restitution by expliciting (possibly caricatured) musical gestures, primarily directed towards an audience. Rather, human performance factors can be considered as fundamental structuring elements in the writing (or thinking, in the case of improvisation) of interactive Computer Music. As such, they are both meaningful and relevant even in the absence of performance, during any individual or collective creative processes.

Contexts \& Expectations Considerations such as those presented above stem at least partially from heterogeneous conceptions of what could be identified as a performance according to composers, interprets or the audience - and, by extension, what each considers important or acceptable as a Computer Music performance. They certainly result in distinct expectations from each party towards the others. These co-expectations will tend to match if the context of the gathering is clearly specified: is it entertainment? A formal representation pertaining to a strongly-codified music genre? A scientific and technical proof of concept? An exploratory approach? An organic and open artistic journey? We are, of course, in no position to judge of the relative artistic validity of any of these contexts, however, finding which context Orcæ's performances "fit into" and which expectations we will confront has been a matter of trial and error.

Orcae's concerns Given that our public performances are constituted entirely of spontaneous real time improvisation, an inherent aspect of trust must be to installed between the audience and us. We invite them to embark on an open sound exploration, knowing fully well that it could be transcendental... or uncomfortable... or just very boring. 
That being said, two recurring questions still obsess us and remain largely unanswered. The first, regularly expressed by the audience is : "who is doing what?". The subsequent second question being then "what should we explain to the audience beforehand, or what should we show, of what actually goes on during our performances?". Should we stick to a purely acousmatic listening experience and hide behind curtains, should we face the audience even though we barely seem to move during the whole session, should we visually project parts of our tools/screens (as a Causal augmentation) or should we go all out and build a complete dynamic scenography and audio-visual counterpart (as an Abstract augmentation)?

We seek for simplicity, and if we were to consider only ourselves (as is the case during private sessions - which in the end are simply performances in which we are both the performers and the listeners), we would not even think about anything but the sound for itself, disembodied of its producers. The fact that the performance aspect might not be seen at all or even known from the audience make little difference to us. But it clearly does for the audience. And while the literature largely states that fact, each one of our performances has been an occasion to measure it. We have played in various contexts and configurations (music only or working in collaboration with visual artists, playing on stage or amidst the listeners, fantastic to disastrous listening conditions, etc.) to various audiences, each time expliciting the bare minimum of our process (if we did so at all). Sometimes, the expectations of the audience converged with ours, some other time they did not. And the questions remain.

Further still, while the essence of our music may not have changed (too) drastically depending on these performance contexts, our subjective experience of each of them undeniably differs from the experience of private sessions. In other words, we don't feel any need to be considered as performers, however being put in a performing position/context significantly impacts our process.

\subsection{Improvisation}

In this section, we will not address the notion of improvisation in regard to the notion of composition. While the historical interest accorded to each has been very uneven (with a clear emphasis on composition, at least in western culture), numerous works have since proposed ways to formalize their relative positioning (see Sarath [3], Smith and Dean [4], Andy Hamilton [5]). We will restrain ourselves to the matter of musical improvisation involving computers. This specific field has seen distinct kinds of practices emerge and develop since the earliest ages of computer sciences. The first one would be to consider the Computer-as-improviser, able to generate structured musical information (e.g. MIDI then rendered by synthesizers). The second practice considers the Computer-as-instrument and emerges from the possibility of calculating realtime streams of synthesized or transformed audio data [6].

The practice of the authors within Orcæ is clearly positioned in resonance with the latter, in the sense that the computer is not perceived as an agent whose role is to respond creatively to the player's input (for instance by following 
procedural rules), but is instead considered as an extensively controllable and reconfigurable instrument that allows for each parameter of each sound-producing process to be observable, editable or even stoppable at any given time ${ }^{7}$.

Below, we will contextualize our approach and practice of computer music improvisation. From there, in the next section, we will posit that this context brings forth a second level of improvisation, referring to real-time design/deconstruction/re-construction of computer-based instruments.

Orcæ's improvisational process can be identified as pertaining to the codes of self-idiomatic music, as defined by Michael Bullock [7] (building upon Derek Bailey's term of non-idiomatic music):

self-idiomatic music is the concentration on sound-making actions for their own productive potential rather than in the service of representation of an external, received idiomatic identity.

There is generally no prior agreement between players regarding any thematic, musical or stylistic directions, be it harmonically (no set key or preference for tonal or atonal material) or rhythmically (no shared tempo or clock synchronisation between machines). Sessions pass without any form of communication other than the sound itself.

Active listening is pivotal to collective improvisation ${ }^{8}$ and may be even more so in this case, as each player's gestures are essentially limited to clicking, occasionally typing, and of course the infamous "knob twiddling". In other words, the sound is the only communication vector between players and the only means for developing a collective musical discourse ${ }^{9}$. As a result, the who-is-doing-what can occasionally become totally blurred, resulting in quite exhilarating moments in which each individual sound component dissolves into a greater entity and none of us are certain of the sound that we are each contributing.

Specificities of public improvisation Marcel Corbussin states that "The possibility of failure is an intrinsic element of all improvised music", and while we certainly fail as much in private sessions as in public ones, the former feels much safer than the latter (at least for two of the three players). We tend to aim for a more "controlled" experience during public performances, often restraining

\footnotetext{
7 This doesn't mean that we don't use emergent or chaotic sound processes (i.e. strongly nonlinear systems or feedback loops) but we don't consider the computer to be improvising in these cases - an electric guitarist controlling amplifier feedback is still a musician playing an instrument, even if the instrumental system is no longer passive in the mechanical/electrical sense.

8 Marcel Cobussen [8]: "the constant process of decision-making that takes place during an improvisation is for a large part based on the listening attitude of the musicians involved."

9 The degree of engagement and pleasure experienced during a public performance is then highly dependant on the quality of sound monitoring. Proper channels for this communication have to exist and low end systems can easily lead to frustration or even jeopardize the whole process.
} 
our exploration of more "extreme" sonic territories, partly because there is a risk of producing uncomfortable sounds for the audience - but possibly because certain fears and inhibitions reappear in a public setting. Conversely, being in front of an audience yields a strong tension that develops focus and the feeling of flow, and as a result time seems to fly during public performances, to the point where it can be very hard for us to remember what actually happened ${ }^{10}$.

Another consideration is that it may be difficult for a member of the audience to know, based solely on our performance, if the music is improvised or not especially since we are not concerned with effort-based control gestures and so forth. Knowledge about how a piece of music was or is being produced has a significant impact on the listener's judgement [9], therefore we do ask ourselves if performances should start with a little disclaimer ("be nice, it's impro!"). Nevertheless, doing so may result in the audience focusing on us as performers, on what we are doing, how we are controlling sounds... whereas our aim is for the sound to be the object of interest in and for itself. As of yet we chose to say nothing beforehand.

Increasing risk - Alleviating failure One thing is for certain, for the audience as for ourselves: improvising computer music demands for perpetual richness, variety, curiosity and surprise. It seems that this posture must be considered on two different time-frames:

There is the time of the performance, during which we try to build an interesting exploration path for (with?) the audience. As expressed in section 3.1, the ability to match the expectations of an audience is of first common interest. This matter turns out to be even more crucial in the context of a free improvisation with computers. It leads Mazierska to express the following advice : "[...] current electronic musicians are free to improvise, but if they want to keep their audience interested, they have to balance this need with the requirement to work with templates and observing traditions" [10]. This statement brings us back to the inherent necessity of a (possibly unconscious) common language between performers, and between performers and audience. Nevertheless we find it important to emphasise on the widest possible interpretation of what these traditions or templates might refer to. We feel that they may include those from codified music, but also those closer to natural or evolving cultural hearing, such as our inherent tendency to relate to organic or artificial sounds through their potential to evoke the physical world, ambiances or even individuals.

And, there is - mostly for us, but maybe also for our most die-hard fans (if we have any) - a need to explore new creative fields on a wider time scale, from one collective public or private session to the next. This need was never defined as a prerequisite of our work together, it simply emerged from the fact that at some point, one of us would identify a routine coming from another (a recurring sound, effect, pattern, way to respond to or place himself in the macro form, etc).

${ }^{10} \mathrm{Ed}$ Sarath [3]: “The improviser experiences time in an inner-directed, or 'vertical' manner, where the present is heightened and the past and future are perceptually subordinated". 
For some reason, being spotted was spontaneously felt as a personal failure in contributing to the collective effort of improvisation, and it progressively pushed each of us to rethink and reinvent our improvisation processes. This ultimately led to deconstruct the very notion of "musical instrument" and widen the scope of improvisation from sound only, to the low-level elements allowing us to produce it. In other words, one of our common practices now consists in starting from an entirely blank page/patch at the beginning of every session. As if the significant increase in risk was somehow the safest way not to fail our pairs or the audience.

\section{Synchronous Improvisation of Instruments and Music}

On the topic of the use of computers in improvised music, Frisk [11] expressed:

A computer does not have a sound but rather comprises the possibility of (nearly) any sound [...] to say that any sound is possible is not quite true [...]

the kind of minute variation and dynamic change that constitute the very notion of a musical sound is still difficult to achieve on the computer. This is a programming challenge, a need to further develop synthesis techniques, but it is also a question of the interface between musician and computer ${ }^{11}$

Despite the ambiguous notion of musical sound, this statement relates directly to Orcæ's posture towards tools for Computer Music, and the need to investigate new paradigms of improvising these tools.

Indeed, since the late nineties research in software environments and programming languages for Computer Music have led to several tools - of both high and low level - that allow performers to program them and produce sound in real-time. The strongest movement that inherently carries such possibilities is Live Coding: "Live coding is the writing of rules in a Turing complete language while they are followed, in order to improvise time based art such as music, video animation or dance" [12]. It brings together a large community of performers/developers (for the most part academics or close to academy) around tools such as SuperCollider and Chuck. Another tool that worth mentioning is the Reactable [13], a - potentially collective - hardware interface that engraves physical objects with logical functions to be assembled on a visual display. In fact, it stands as a tangible version of visual programming environments such as PureData and Max/MSP, which allow for what can be called live-patching although it is not their most frequent use-case. And, finally another very interesting work relying on lower-level programming is the UrSound audio and multimedia engine [14].

Although the listing of these dedicated and often expert environments is relevant, luckily one does not need to graduate in computer sciences in order to explore this path. As a matter of fact, two of Orcæ's three members improvise using commercial software such as Ableton Live and Reason.

11 This resonates directly with what Max Mathews stated at the dawn of Computer Music: the perspective of an infinite versus our ability to explore it in a sensible way. 


\subsection{Instrument Improvisation in Orcæ}

Regarding musician and instrument in improvisation, Cobussen states :

The instrument does not simply yield passively to the desires of the musician. Likewise, he does not just bend it to his own will with no consideration to the resistance it offers. Rather musician and instrument meet, each drawing the other out of its native territory.

Embracing the computer instrument as part of the improvisation process precisely offers a means to perpetually renew this play of resistance and exploration. In our case, novelty and personality in improvisation do not stem from virtuosity developed in relation to a given computer-instrument - something we see as difficult and possibly restrictive given the diversity and rapid evolution of available tools -, but in systematically "(re)discovering the specific characteristics of their instrument, its unique and perhaps unexpected possibilities".

In-session tool improvisation is mostly practiced by players B and C, as they generally start with blank Live or Reason workspaces. Although these environments possess advanced mapping possibilities for control surfaces, the players use almost exclusively the mouse \& keyboard. Indeed, control mapping is usually used when performing with pre-structured musical environments, whereas player $\mathrm{B}$ and C's processes are qualitatively different in that they consist in creating work/creation environments in real time. To this day, the classic mouse/keyboard combination remains the most effective way to perform such operations.

Pre-session tool improvisation is practiced by Player A, whose main tool is Max/MSP. Live-patching entire instruments from scratch during sessions is rather tricky, so they are generally conceived beforehand. However, we still refer to them as improvised tools as they are often devised rapidly in the days or hours preceding a session, and are experimented in a work-in-progress state, tweaked, broken and fixed on the fly. The few of these experiments that stabilise over time into reusable tools are generally mapped to a control surface in order to facilitate exploration of the offered parameter space.

Imperfect digital tools In each of the above, one of the factors that drew us towards improvising Computer Music tools is the fascination for imperfections, a term often cited as a central aspect of musical improvisation [5]. So what if what we're doing is inducing hard audio-clipping? Or if we generate harsh digital artefacts every time we change the length of a delay line? In our short experience as recovering digital signal processing geeks / fresh young improvisers, all of these are simply spaces to explore and to work with - and while some choices may be frowned upon from a technical standpoint, who is to say that they can't be musically relevant? 


\section{Discussion}

Although the positions advanced in this work inevitably fall into the domain of subjective evaluation and self-analysis of our own artistic process, it seems to us that the freely-improvised Computer Music context constitutes a unique and intriguing object of study. We believe that this improvisation scenario differs significantly from improvising on traditional instruments and that, in addition to the vast creative potential that it harbors, brings forth enticing interrogations as to multilayered improvisation paradigms and the creative exploration that occurs during musician-instrument interaction.

The format of this first attempt has led us to skim over a number of key considerations such as emergent collaborative creation, or multi-modal collective improvisation and performance. These will be for another occasion.

Finally, as a collective of improvisers who have never attempted to formalise to their creative process and approach to improvisation before writing this paper, one question remains... will this new awareness affect the way we improvise and perform together from this day on?

\section{References}

1. Schloss, W.: Using Contemporary Technology in Live Performance: The Dilemma of the Performer. Journal of New Music Research, Issue 32, p239-242. (2003)

2. Garnett, G.E.: The Aesthetics of Interactive Computer Music. Computer Music Journal, Vol. 25, No. 1, Aesthetics in Computer Music, pp. 21-33 (2001)

3. Sarath, E.: A New Look at Improvisation. Journal of Music Theory, Vol. 40, No. 1 (Spring, 1996), p1-38 (1996)

4. Smith, H., Dean, R.T.: Improvisation, Hypermedia and the Arts since 1945 (Performing Art Study). Amsterdam: Harwood Academic Publishers (1997)

5. Hamilton, A.: The art of improvisation and the aesthetics of imperfection. The British Journal of Aesthetics, Volume 40, Issue 1 (2000)

6. Dean, R.T.: Envisaging improvisation in future computer music. In R. T. Dean, ed. 2009. The Oxford Handbook of Computer Music. New York: Oxford Univeristy Press, p133-147 (2009)

7. Bullock, M.T.: Self-Idiomatic Music: An Introduction. Leonardo Music Journal, Volume 43, p141-144 (2010)

8. Cobussen, M.A.: Improvisation. An Annotated Inventory. New Sound, Issue 32, p9-22 (2008)

9. Canonne, C.: Listening to Improvisation. Eastern Division Meeting of the American Society for Aesthetics, Philadelphia (2017)

10. Mazierska, E.: Improvisation in Electronic Music - The Case of Vienna Electronica. Open Cultural Studies. 2. 553-561 (2018)

11. Frisk, H.: Improvisation, Computers, and Primary Process: Why improvise with computers?. New Sound, Issue 32, p107-118 (2008)

12. McLean, A., Wiggins, G.: Live Coding towards Computational Creativity. In Proceedings of 2010 Conference, Lisbon (2010)

13. Kaltenbrunner, M., Geiger G., Jordà S.: Dynamic patches for live musical performance. In Proceedings of 2004 NIME Conference, Singapore (2004)

14. Essel, G.: UrSound, Live Patching of Audio and Multimedia Using a Multi-Rate Normed Single-Stream Data-Flow Engine. ICMC 2010 Proceedings, Lisbon (2010) 